\title{
OPTIMASI DISTRIBUSI SEMEN PT. XYZ DENGAN MODIFIKASI MODEL TRANSPORTASI
}

\section{OPTIMIZING CEMENT DISTRIBUTION IN PT. XYZ WITH MODIFIED TRANSPORTATION MODEL}

\author{
${ }^{1}$ Era Febriana Aqidawati, ${ }^{2}$ Nino Rahadian, ${ }^{3}$ Zikri Haqqoni, ${ }^{4}$ Y uniaristanto, ${ }^{5}$ Wahyudi Sutopo \\ 1,2,3,4,5Program Studi Teknik Industri, Fakultas Teknik, Universitas Sebelas Maret \\ 1erafebriana1@gmail.com, ${ }^{2}$ nrahadian@gmail.com, ${ }^{3}$ haqqonizikri@gmail.com, ${ }^{4}$ yuniaristanto@ft.uns.ac.id, ${ }^{5}$ wahyudisutopo@staff.uns.ac.id
}

\begin{abstract}
Abstrak-Transportasi memainkan peran penting bagi industri ini karena produsen memiliki ketertarikan untuk mengirim barang mereka ke pelanggan tepat waktu, tepat dan barang berada dalam kondisi baik. Sari dkk (2013) telah mengoptimalkan masalah transportasi pada sistem distribusi semen PT. XYZ Pada artikel tersebut, optimasi dilakukan dengan meminimalkan biaya transportasi dengan menggunakan solusi fiskal awal dengan metode Least Cost dan menghitung solusi optimal dengan metode potensial. Namun, dalam perhitungan tersebut, faktor jarak antara gudang dan distribusi dan kapasitas transportasi tidak dipertimbangkan. Padahal, dalam mendistribusikan produk, faktor jarak tempuh menjadi cukup penting untuk dipertimbangkan karena melibatkan banyak hal dalam operasinya. Oleh karena itu, pada artikel ini, biaya distribusi semen akan dioptimalkan dengan menggunakan model modifikasi dari model transportasi yang digunakan di artikel Sari et al (2013).
\end{abstract}

Kata kunci: model modifikasi, optimasi, transportasi

Abstract-Transportation plays an important role for the industry because the producers have an interest in getting their goods transported to the customer on time, at the exact spot and goods are in good condition. Sari et al (2013) have optimized the transportation problem on the cement distribution system of PT. $\mathrm{XYZ}$. In those article, optimization is done by minimizing transportation costs using the initial fiscal solution with the Least Cost method and calculating the optimal solution with potential method. However, in that calculation, the distance factor between the warehouse and the distribution and transport capacity is not considered. In fact, in distributing a product, the mileage factor becomes important enough to be considered because it involves many things in its operation. Therefore, in this article, the cement distribution cost will be optimized by using modified model of the transportation model used in Sari et al (2013).

Keywords: modified model, optimization, transportation.

\section{PENDAHULUAN}

Transportasi mempunyai peranan penting bagi industri karena produsen mempunyai kepentingan agar barangnya diangkut sampai kepada konsumen tepat waktu, tepat pada tempat yang ditentukan dan barang dalam kondisi baik [1]. Kasus transportasi timbul ketika suatu

$\begin{array}{ll}\text { Sejarah artikel } & \\ \text { Diterima redaksi: } & : \text { 01 Desember } 2017 \\ \text { Revisi akhir } & : \text { 17 Desember } 2017 \\ \text { Diterbitkan online } & : \text { 28 Desembe } 2017\end{array}$

perusahaan mencoba menentukan cara pengiriman (pendistribusian) suatu jenis barang (item) dari beberapa sumber (lokasi penawaran) ke beberapa tujuan (lokasi permintaan) [2]. Setiap industri pasti menginginkan biaya yang minimum untuk proses transportasi, sehingga diperlukan suatu strategi pemecahan masalah yang bisa memberikan solusi yang optimal.

Metode transportasi merupakan suatu model yang digunakan untuk mengatur distribusi dari sumber-sumber yang menyediakan produk yang utama ke tempat-tempat yang membutuhkan secara optimal. Alokasi produk ini harus diatur sedemikian rupa, karena terdapat perbedaan biaya-biaya alokasi dari satu sumber ke tempat tujuan-tujun yang bebeda. [3]. Pada prinsipnya fungsi ini bertujuan untuk menciptakan pelayanan yang tinggi ke customer yang bisa dilihat dari tingkat service level yang dicapai, kecepatan pengiriman, kesempurnaan barang sampai ke tangan customer, serta pelayanan purna jual yang memuaskan [4]. Dengan adanya perencanaan pengeluaran transportasi maka akan diperoleh peningkatan keuntungan karena mampu meminimalkan biaya transportasi dan permintaan pasar juga dapat terpenuhi dengan baik [1].

Sari dkk [5] telah melakukan optimasi masalah transportasi pada sistem distribusi semen PT. XYZ. Dalam artikel ini, optimasi dilakukan dengan cara meminimumkan biaya transportasi menggunakan solusi fisibel awal dengan metode Least Cost dan penghitungan solusi optimal dengan metode potensial [5]. Namun, dalam perhitungan tersebut, faktor jarak antara gudang dengan tujuan distribusi dan kapasitas kendaraan angkut belum dipertimbangkan. Padahal, dalam mendistribusikan suatu produk, faktor jarak tempuh menjadi hal yang cukup penting untuk diperhatikan karena melibatkan banyak hal dalam pengoperasiannya. Misalnya jumlah armada yang dibutuhkan, biaya bahan bakar, dan rute pengiriman barang [6]. Oleh karena itu, dalam artikel ini akan dilakukan optimasi pendistribusian semen dengan menggunakan model yang dimodifikasi dari model transportasi yang digunakan pada artikel Sari dkk [5].

Ada sejumlah penelitian yang mengkaji penyelesaian masalah transportasi untuk distribusi barang, antara lain adalah distribusi minuman [7], produk sanitary [8] dan gula merah [9]. Selain itu, penentuan jarak terpendek pada jalur distribusi juga menjadi sorotan dalam penyelesaian permasalahan transportasi [10]. Biaya transportasi yang optimal dapat dipeoleh menggunakan metode saving matrix dengan mempertimbangkan jarak dan kapasitas alat angkut dalam 
penentuan jalur distribusi [11], [12]. Sementara itu, penggunaan metode Insertion Intra Route dapat digunakan untuk meminimasi jarak dan waktu penyelesaian pada setiap kegiatan pendistribusian [13]. Sedangkan pencarian rute terbaik dapat dilakukan dengan mempertimbangkan berat barang terhadap daya tampung kendaraan dalam distribusi air minum dalam kemasan [14].

Artikel ini disusun sebagai berikut. Pada bagian 1 disajikan latar belakang penelitian dan diuraikan permasalahan dalam sistem nyata. Pada bagian 2, disajikan studi literatur mengenai model trasportasi dasar yang akan dikembangkan. Pada bagian 3, dijelaskan metodologi penelitian untuk memecahkan masalah. Hasil dan pembahasan disajikan pada bagian 4 dan simpulan disajikan pada bagian 5 .

\section{STUDILITERATUR}

Masalah transportasi merupakan salah satu permasalahan khusus dalam linear programming. Ciri-ciri khusus persoalan transportasi adalah sebagai berikut:

1. Terdapat sejumlah sumber dan sejumlah tujuan tertentu

2. Jumlah komoditi yang didistribusikan besarnya tertentu

3. Jumlah barang yang dikirim besarnya sesuai dengan kapasitas sumber

4. Biaya pengangkutan besarnya tertentu

Model transportasi dapat dirumuskan sebagai berikut [15] :

Fungsi Tujuan:

$$
\mathrm{Z}_{\min }=\sum_{\mathrm{i}=1}^{\mathrm{m}} \sum_{\mathrm{i}=1}^{\mathrm{n}} \mathrm{C}_{\mathrm{ij}} \mathrm{x}_{\mathrm{ij}}
$$

Fungsi kendala:

$$
\begin{aligned}
& \sum_{\mathrm{i}=1}^{\mathrm{m}} \mathrm{x}_{\mathrm{ij}} \leq \mathrm{S}_{\mathrm{i}} ; \mathrm{i}=1,2, \ldots, \mathrm{m} \\
& \sum_{\mathrm{i}=1}^{\mathrm{m}} \mathrm{x}_{\mathrm{ij}} \leq \mathrm{D}_{\mathrm{j}} ; \mathrm{i}=1,2, \ldots, \mathrm{n}
\end{aligned}
$$

dengan:

$S_{i}=$ kapasitas persediaan dari gudang $\mathrm{i}$

$D_{j}=$ jumlah permintaan di tujuan $\mathrm{j}$

$x_{i j}=$ jumlah unit produk yang dikirim dari gudang $\mathrm{i}$ ke tujuan $\mathrm{j}$

$C_{i j}=$ biaya pengiriman per unit produk dari gudang $\mathrm{i}$ ke tujuan j

Bravo dan Vidal [16] dalam telah melakukan tinjauan secara rinci terkait tren fungsi transportasi dalam optimasi rantai pasok. Dalam tulisannya, Bravo dan Vidal mengusulkan beberapa rekomendasi untuk pengembangan model fungsi transportasi, di antaranya adalah memasukkan pertimbangan apakah armada transportasi yang digunakan adalah milik pribadi atau outsource. Jika milik pribadi, maka strategi costing yang digunakan adalah cost per distance dan cost per unit shipped. Jika outsource, maka strategi costing yang digunakan adalah product-based cost yang mempertimbangkan atribut produk (bobot dan volume) dan tipe rute yang dilewati [16].

\section{METODOLOGI PENELITIAN}

\section{A. Alur Pengembangan Model}

Metode yang dilakukan dalam artikel ini adalah pengembangan model transportasi yang digunakan pada artikel Sari dkk [5]. Faktor tambahan yang akan diakomodasi ke dalam model adalah jarak antara gudang dengan tujuan distribusi dan kapasitas kendaraan angkut. Perbedaan antara model lama dengan model yang baru terletak pada fungsi tujuan (objective function), variabel keputusan dan fungsi kendala (constraint). Data-data yang digunakan sebagai input dalam model tetap berasal dari artikel Sari dkk [5]. Gambar 1 menunjukkan alur pengembangan model.

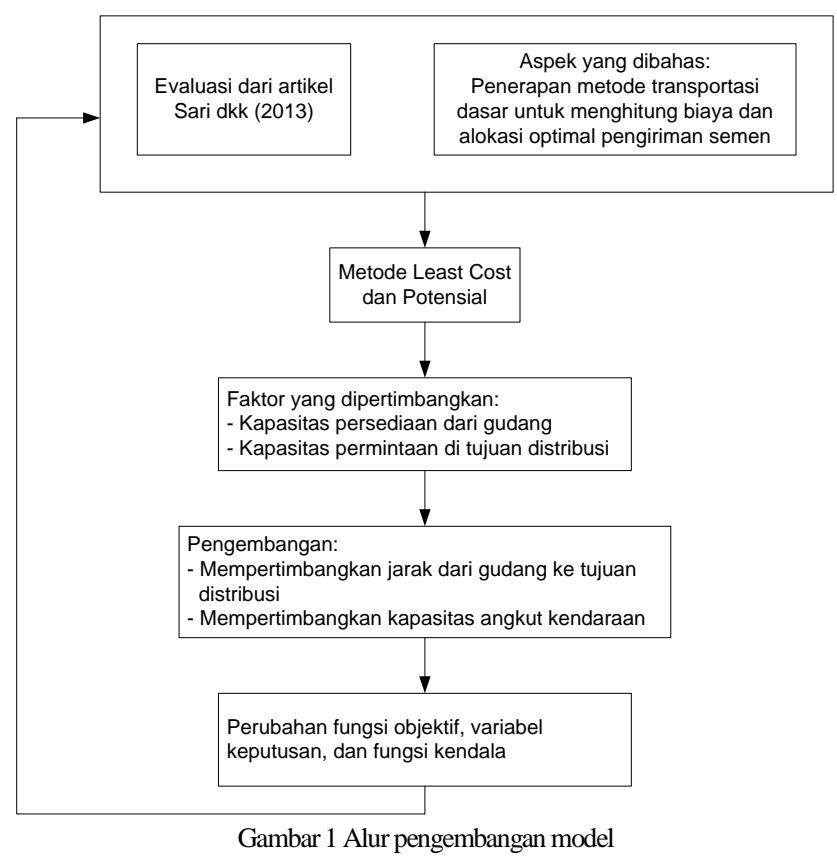

B. Formulasi Model

Fungsi tujuan pada model awal adalah minimasi ongkos kirim per unit produk. Kemudian ditambahkan objektif berupa minimasi ongkos kirim per kilometer $(\mathrm{km})$ jarak yang ditempuh oleh kendaraan, seperti yang ditunjukkan pada persamaan (4). Fungsi kendala awal berupa batasan kuantitas pengiriman yang tidak melebihi kapasitas persediaan dari gudang (5) dan sesuai dengan permintaan di setiap tujuan (6). Sementara itu, fungsi kendala yang ditambahkan berupa batasan agar kuantitas semen yang dikirimkan tidak melebihi kapasitas angkut kendaraan yang mengangkut semen sebanyak $y_{i j}$ (7). Variabel keputusan yang awalnya berupa kuantitas pengiriman dari gudang ke tujuan $\left(x_{i j}\right)$, ditambah dengan variabel $y_{i j}$ yang menyatakan banyaknya pengiriman yang harus dilakukan oleh satu kendaraan dari gudang ke tujuan distribusi.

$\begin{array}{cl}\text { Parameter } & \\ C_{i j} & =\text { biaya pengiriman per unit produk dari gudang } \mathrm{i} \text { ke } \\ & \text { tujuan distribusi } \mathrm{j} \\ \mathrm{Cd} & =\text { biaya pengiriman per km jarak yang ditempuh } \\ \text { dist }_{i j} & =\text { jarak yang ditempuh dari gudang } \mathrm{i} \text { ke tujuan } \\ & \text { distribusi } \mathrm{j} \text { kembali lagi ke gudang } \mathrm{i} \\ S_{i} & =\text { kapasitas persediaan dari gudang } \mathrm{i} \\ D_{j} & =\text { jumlah permintaan di tujuan distribusi } \mathrm{j} \\ \text { Cap } & =\text { kapasitas angkut kendaraan distribusi }\end{array}$

Variabel Keputusan

$x_{i j} \quad=$ jumlah unit produk yang dikirim dari gudang $\mathrm{i}$ ke tujuan distribusi $\mathrm{j}$

$y_{i j} \quad=$ banyaknya pengiriman yang dilakukan oleh satu kendaraan dari gudang $\mathrm{i}$ ke tujuan distribusi $\mathrm{j}$ 
Fungsi Objektif

$$
\operatorname{Min} \sum_{i \epsilon I} \sum_{j \epsilon J} C_{i j} x_{i j}+\sum_{i \epsilon I} \sum_{j \epsilon J} C d d i s t_{i j} y_{i j}
$$

Fungsi Kendala

$$
\begin{aligned}
& \sum_{j \in J} x_{i j} \leq S_{i}, \forall i \in I \\
& \sum_{i \in I} x_{i j} \leq D_{j}, \forall j \in J \\
& x_{i j} \leq \operatorname{Cap} y_{i j}, \forall i \in I, j \in J \\
& y_{i j} \geq 0, \forall i \in I, j \in J
\end{aligned}
$$

\section{HASIL DAN ANALISIS}

Model pengembangan dari artikel Sari dkk [5] diterapkan untuk optimasi distribusi semen PT. XYZ. Permasalahan yang dihadapi perusahaan adalah besarnya biaya pendistribusian produk di PT. XYZ dari beberapa gudang ke beberapa lokasi permintaan (tujuan). PT XYZ memiliki 3 gudang yang terletak di lokasi yang terpisah, yaitu di Panjang, Paya Rumput, dan Tebing Tinggi. Perusahaan mendapat permintaan dari 6 toko bangunan dan 2 perusahaan konsumen, yaitu UD Sakti, UD Paten, UD Utama, UD Indomas, UD Jecky, PT Nidya, PT Waskita, dan UD Harco. Data yang digunakan adalah data pada tahun 2012 yang berasal dari PT. XYZ. Data jumlah permintaan semen dapat dilihat pada Tabel I, jumlah kapasitas persediaan semen di tiap gudang dapat dilihat pada Tabel II, biaya pengiriman dapat dilihat pada Tabel III, dan jarak tempuh dari gudang ke tujuan dapat dilihat pada Tabel IV. Kemudian data diolah menggunakan software ILOG CPLEX untuk mencari solusi optimal dari kasus ini.

TABELI

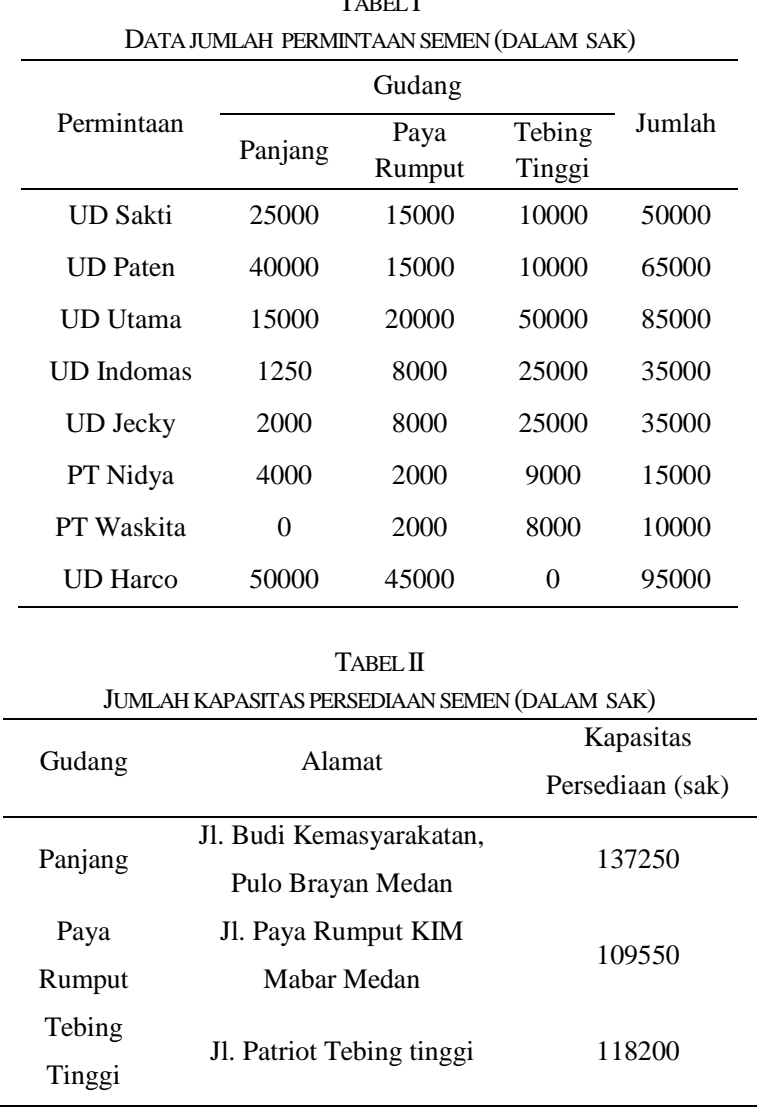

DOI: https://doi.org/10.25124/jrsi.v4i02.288

TABEL III

BIAYA PENGIRIMAN PER SAK SEMEN

\begin{tabular}{cccc}
\hline \multirow{4}{*}{ Tujuan } & \multicolumn{3}{c}{ Biaya angkut dari gudang (Rp/sak) } \\
\cline { 2 - 4 } & Panjang & Paya Rumput & Tebing Tinggi \\
\hline UD Sakti & 1000 & 1500 & 2000 \\
UD Paten & 1500 & 1800 & 2300 \\
UD Utama & 1800 & 2000 & 1200 \\
UD Indomas & 2300 & 2500 & 1800 \\
UD Jecky & 2500 & 3000 & 1500 \\
PT Nidya & 1800 & 2000 & 1000 \\
PT Waskita & 1800 & 2200 & 800 \\
UD Harco & 3500 & 4000 & 5000 \\
\hline
\end{tabular}

TABEL IV

JARAK TEMPUH DARI GUDANG KETUJUAN

\begin{tabular}{cccc}
\multicolumn{3}{c}{ JARAK TEMPUHDARIGUDANG KETUJUAN } \\
\cline { 2 - 4 } Tujuan & \multicolumn{3}{c}{ Jarak dari gudang $(\mathrm{km})$} \\
\cline { 2 - 4 } & Panjang & Paya Rumput & Tebing Tinggi \\
\hline UD Sakti & 53.37 & 61.85 & 94.60 \\
UD Paten & 77.52 & 45.58 & 78.49 \\
UD Utama & 85.43 & 47.07 & 79.04 \\
UD Indomas & 101.95 & 35.10 & 63.74 \\
UD Jecky & 106.56 & 32.90 & 59.81 \\
PT Nidya & 115.66 & 43.95 & 67.22 \\
PT Waskita & 110.88 & 89.16 & 117.49 \\
UD Harco & 140.27 & 85.07 & 104.94 \\
\hline
\end{tabular}

TABEL V

JUMLAH UNIT SEMEN YANG DIKIRIM DARI GUDANG KE TUJUAN

\begin{tabular}{cccc}
\hline \multirow{2}{*}{ Tujuan } & \multicolumn{3}{c}{ Kuantitas pengiriman dari gudang (sak) } \\
\cline { 2 - 4 } & Panjang & Paya Rumput & Tebing Tinggi \\
\hline UD Sakti & 50000 & 0 & 0 \\
UD Paten & 64500 & 500 & 0 \\
UD Utama & 0 & 26550 & 58450 \\
UD Indomas & 0 & 10000 & 0 \\
UD Jecky & 0 & 0 & 35000 \\
PT Nidya & 0 & 0 & 15000 \\
PT Waskita & 250 & 0 & 9750 \\
UD Harco & 22500 & 72500 & 0 \\
\hline
\end{tabular}

Kendaraan yang digunakan untuk mengangkut semen adalah truk tronton dengan kapasitas 30 ton atau sama dengan 750 sak semen. Biaya pengiriman per km sebesar Rp 7.000,-. PT XYZ memiliki sejumlah truk di masing-masing gudang, yaitu sebanyak 15 truk di gudang Panjang, 10 truk di Paya Rumput dan 12 truk di Tebing Tinggi.

Solusi dari model dan data yang telah diolah ditunjukkan pada Tabel V dan Tabel IV. Berdasarkan Tabel V, diketahui bahwa UD Sakti, UD Paten, PT Waskita dan UD Harco mendapat pasokan 
semen dari gudang Panjang masing-masing sebanyak 50.000, 64.500, 250 dan 22.500 sak. Sementara itu, persediaan semen di gudang Paya Rumput digunakan untuk memasok semen ke UD Paten, UD Utama, UD Indomas dan UD Harco masing-masing sebanyak 500, 26.550, 10.000 dan 72.500 sak. Selain itu, UD Utama, UD Jecky, PT Nidya dan PT Waskita juga mendapat pasokan dari gudang Tebing Tinggi masing-masing sebanyak 58.450, 35.000, 15.000 dan 9.750 sak.

Berdasarkan Tabel VI, diketahui bahwa dengan menggunakan satu truk diperlukan pengiriman dari gudang Panjang ke tujuan masing-masing sebanyak 67 kali ke UD Sakti, 86 kali ke UD Paten, 1 kali ke PT Waskita dan 30 kali ke UD Harco. Sementara itu, jumlah pengiriman dari Paya Rumput adalah sebanyak 1 kali ke UD Paten, 36 kali ke UD Utama, 14 kali ke UD Indomas dan 97 kali ke UD Harco. Sedangkan jumlah pengiriman yang harus dilakukan dari Tebing Tinggi jika menggunakan satu truk adalah sebanyak 78 kali ke UD Utama, 47 kali ke UD Jecky, 20 kali ke PT Nidya dan 13 kali ke PT Waskita. Dari hasil running model, diperoleh solusi optimal biaya pengiriman total sebesar Rp. 998.639.180,-.

TABEL VI JUMLAH PENGRIMAN DARI GUDANG KE TUJUAN

\begin{tabular}{cccc}
\hline \multirow{2}{*}{ Tujuan } & \multicolumn{3}{c}{ Jumlah pengiriman dari gudang } \\
\cline { 2 - 4 } & Panjang & Paya Rumput & Tebing Tinggi \\
\hline UD Sakti & 67 & 0 & 0 \\
UD Paten & 86 & 1 & 0 \\
UD Utama & 0 & 36 & 78 \\
UD Indomas & 0 & 14 & 0 \\
UD Jecky & 0 & 0 & 47 \\
PT Nidya & 0 & 0 & 20 \\
PT Waskita & 1 & 0 & 13 \\
UD Harco & 30 & 97 & 0 \\
\hline
\end{tabular}

TABEL VII

PERBANDINGAN KONDISI SEBELUM DAN SETELAH PENGEMBANGAN (LANJUTAN)

\begin{tabular}{cll}
\hline Aspek & \multicolumn{1}{c}{ Sebelum } & Setelah Pengembangan \\
& Pengembangan & \\
\hline $\begin{array}{c}\text { Model yang } \\
\text { digunakan }\end{array}$ & $\begin{array}{l}\text { Model } \\
\text { transportasi }\end{array}$ & $\begin{array}{l}\text { Modifikasi model transportasi } \\
\text { dasar }\end{array}$ \\
& Kasar & - Kapasitas persediaan dari \\
& Kapasitas & gudang \\
persediaan dari & - Kapasitas permintaan di tiap \\
dipertimbangkan & gudang dan & tujuan \\
& kapasitas & - Jarak tempuh dari tiap gudang \\
& permintaan di & ke masing-masing tujuan \\
& tiap tujuan & - Kapasitas angkut kendaraan \\
& Biaya & - Biaya pengiriman per unit \\
& pengiriman per & semen (dalam sak) dari tiap \\
& unit semen & gudang ke masing-masing \\
Komponen & (dalam sak) dari & tujuan \\
biaya & tiap gudang ke & - Biaya pengiriman per km \\
& masing-masing & jarak yang ditempuh dari \\
& tujuan & gudang ke tujuan \\
\hline
\end{tabular}

TABEL VII

PERBANDINGAN KONDISI SEBELUM DAN SETELAH PENGEMBANGAN

\begin{tabular}{clc}
\hline Aspek & \multicolumn{1}{c}{$\begin{array}{c}\text { Sebelum } \\
\text { Pengembangan }\end{array}$} & \multicolumn{1}{c}{ Setelah Pengembangan } \\
\hline & $\begin{array}{l}\text { Jumlah unit } \\
\text { produk yang } \\
\text { dikirim dari tiap } \\
\text { Vudang ke } \\
\text { keputusan }\end{array}$ & $\begin{array}{c}\text { - Jumlah unit produk yang } \\
\text { dikirim dari tiap gudang ke } \\
\text { masing-masing tujuan } \\
\text { distribusi }\end{array}$ \\
& $\begin{array}{l}\text { - Banyaknya pengiriman yang } \\
\text { dilakukan distribusi } \\
\text { kendaraan dari gudang ke } \\
\text { tujuan distribusi }\end{array}$ \\
$\begin{array}{c}\text { Solusi optimal } \\
\text { total biaya } \\
\text { pengiriman }\end{array}$ & Rp. 727.315.000,- & Rp. 998.639.180,-- \\
\hline
\end{tabular}

Berdasarkan running model transportasi yang telah dilakukan, diperoleh perbandingan yang membedakan antara kondisi sebelum dan sesudah model dikembangkan. Perbandingan tersebut disajikan pada Tabel VII. Perlu diketahui bahwa solusi optimal total biaya pengiriman yang dihasilkan dari model yang telah dikembangkan lebih besar dari solusi optimal sebelum pengembangan. Hal ini disebabkan karena biaya pengiriman per km dimasukkan ke dalam komponen biaya pada model pengembangan, sehingga biaya pengiriman akan semakin bertambah seiring bertambahnya jarak tempuh dari gudang ke tujuan.

\section{KESIMPULAN}

Telah dilakukan pengembangan dari artikel Sari dkk [5] yang membahas mengenai optimasi masalah transportasi pada sistem distribusi semen PT. XYZ menggunakan model transportasi dasar yang dimodifikasi sedemikian rupa dengan menambahkan faktor jarak antara gudang dengan tujuan dan kapasitas angkut kendaraan. Model ini menghasilkan jumlah optimal pengiriman yang diperlukan dan unit yang dikirimkan dari gudang ke tujuan masing-masing. Model ini dapat digunakan manajer logistik sebagai alat bantú dalam pengambilan keputusan untuk menentukan alokasi kuantitas pengiriman ke masing-masing tujuan dari ketiga gudang dan alokasi jumlah kendaraan dari tiap gudang yang harus digunakan untuk mengangkut ke masing-masing tujuan.

\section{DAFTAR PUSTAKA}

[1] Nasution, M.N., Manajemen Transportasi, cetakan ketiga, Ghalia Indonesia, Jakarta, 2008.

[2] Aminudin, Prinsip-Prinsip Riset Operasi. Jakarta: Erlangga, Jakarta, 2005.

[3] Chopra, S. dan Meindl, P., Supply chain management: Strategy, planning, and operations, Prentice Hall, New Jersey, 2001.

[4] Pujawan, I. N., Supply Chain Management, Guna Widya., Surabaya, 2005.

[5] Sari, D.P., Bu'ulolo, F., Ariswoyo, S., Optimasi Masalah Transportasi dengan menggunakan Metode Potensial pada Sistem Distribusi PT. XYZ, Saintia Matematika, Vol. 1, No. 5, 2013, pp. 407-418. 
[6] Mahariani, N.L., Rusindiyanto, Santoso, B., Minimasi Biaya Pendistribusian Pupuk dengan Metode Travelling Salesman Problem (TSP) Studi Kasus PT. Bunga Tani Lamongan, JURNAL TEKMAPRO, Vol 9, No 2, 2014, pp. 147-161.

[7] Harun, I.A., Mahmudy, W.F. \& Yudistira, N., Implementasi evolution strategies untuk penyelesaian vehicle routing problem with time windows pada distribusi minuman soda XYZ, DORO: Repository Jurnal Mahasiswa PTIIK Universitas Brawijaya, vol. 4, no. 1, 2014

[8] Mukhsinin, A., Imran, A., Susanty, S., Penentuan Rute Distribusi CV. IFFA Menggunakan Metode Nearest Neighbour dan Local Search, Reka Integra, Vol. 1, No. 2, 2013, pp. 129-138.

[9] Sari, D.P., Optimasi Distribusi Gula Merah pada UD Sari Bumi Raya Menggunakan Model Transportasi dan Metode Least Cost, Jurnal Online Universitas Dian Nuswantoro, 2014.

[10] Joni, I.D.M.A.B dan Nurcahyawati, V., Penentuan Jarak Terpendek pada Jalur Distribusi Barang di Pulau Jawa dengan Menggunakan Algoritma Genetika, JANAPATI, Volume 1, Nomor 3, 2012, pp. 244-258

[11] Erlina P., Mengoptimalkan Biaya Transportasi untuk Penentuan Jalur Distribusi Produk ' $\mathrm{X}$ ' dengan Metode Saving Matriks, Jurnal Penelitian Ilmu Teknik, Vol.9, No.2, 2009, pp 143-150.

[12] Hasanah, M., Matondang, N., Ishak, A., Penentuan Rute Distribusi Barang yang Optimal dengan Menggunakan Algoritma Heuristik pada PT. XYZ, e-Jurnal Teknik Industri FT USU, Vol 3, No. 3, 2013, pp. 48-51.

[13] Fauzi, A.R. dan Susanty, S., Penentuan Rute Distribusi Tabung Gas Menggunakan Metode (1-0) Insertion Intra Route (Studi Kasus di PT X), Reka Integra, Vol.03, No.01, 2015, pp. 318-328.

[14] Juniarto, S.D., Martiana E., Fariza, A., Prasetyaningrum, I., Optimasi Distribusi Barang Berdasarkan Rute dan Daya Tampung menggunakan Metode Simulated Annealing. EEPIS Final Project, 2011.

[15] Siagian, P, Penelitian Operasional, Universitas Indonesia, Jakarta, 2006.

[16] Bravo, J.J. dan Vidal, C.J. Freight transportation function in supply chain optimization models: A critical review of recent trends. Expert Systems with Applications, Vol 40, 2013, pp. 6742-6757. 